\title{
CONTEÚDOS E SIGNIFICADOS DA SEGREGAÇÃO SOCIOESPACIAL EM IMPERATRIZ- MA: UMA ANÁLISE A PARTIR DA POLÍTICA HABITACIONAL DIFUNDIDA NO CONJUNTO HABITACIONAL ITAMAR GUARÁ I
}

\author{
CONTENTS AND MEANINGS OF SOCIOSPATIAL SEGREGATION IN IMPERATRIZ-MA: AN ANALYSIS OF THE HOUSING \\ POLICY WIDESPREAD IN THE ITAMAR GUARÁ I HOUSING SET
}

\section{RESUMO}

Neste artigo são abordados elementos da configuração da política habitacional desenvolvida na cidade de Imperatriz-MA. Este estudo visa refletir sobre os significados da política de habitação difundida por meio do Programa Minha Casa Minha Vida - PMCMV - no conjunto habitacional Itamar Guará I, implantado nesta cidade no ano de 2012 e suas relações com a segregação socioespacial urbana. Em primeiro momento é destacado como reflexão, a intensificação do processo de urbanização no Brasil que se apresentou de modo complexo, promovendo uma série de problemas sociais, dentre eles, destaca-se a falta de moradia. Em seguida, fez-se um breve contexto da evolução das políticas habitacionais no Brasil, dando ênfase ao PMCMV e suas contradições. Do ponto de vista metodológico, as reflexões aqui realizadas se baseiam nas abordagens marxista e qualitativa e se ampararam na adoção do método dialético, considerando a construção contraditória do espaço urbano na cidade capitalista contemporânea. Utilizamos ainda para a coleta de dados a observação simples e a realização de entrevistas semiestruturadas com os moradores do conjunto habitacional Itamar Guará I.

Palavras-chave: Habitação. Segregação. Política habitacional. Imperatriz. Itamar Guará I.

\begin{abstract}
In this article we present elements of the configuration of the housing policy developed in the city of Imperatriz-MA. This study aims to reflect on the meanings of the housing policy disseminated through the My Home My Life Program PMCMV - in the housing set Itamar Guará I, implanted in this city in the year of 2012 and its relations with the urban sociospatial segregation. In the first moment, the intensification of the urbanization process in Brazil is highlighted as a reflection that presented itself in a complex way, promoting a series of social problems, among them, the lack of housing. Then, a brief context was given to the evolution of housing policies in Brazil, with emphasis on the PMCMV and its contradictions.From the methodological point of view, the reflections made here are based on the Marxist and qualitative approaches and supported the adoption of the dialectical method, considering the contradictory construction of the urban space in the contemporary capitalist city. For data collection, we also used simple observation and semi-structured interviews with residents of the Itamar Guará I housing set.
\end{abstract}

Keywords: Housing. Segregation. Housing policy. Imperatriz. Itamar Guará I.
(D) Kaio de Moura Silva ${ }^{\text {a }}$

iD Jailson de Macedo Sousa ${ }^{a}$

${ }^{a}$ Universidade Estadual da Região Tocantina do Maranhão (UEMASUL), Imperatriz, MA, Brasil

DOI: $10.12957 /$ geouerj.2020.40520

Correpondência: kaiomsil18@gmail.com

Recebido em: 28 fev. 2019 Revisado em: 18 mai. 2020 Aceito em: 3 ago. 2030 


\section{INTRODUÇÃO}

A organização das cidades brasileiras tem sido caracterizada por intensas desigualdades socioespaciais e a segregação se apresenta como conteúdo inerente a estas, denotando graves implicações nos processos de formação e estruturação das cidades.

A segregação na cidade capitalista caracteriza-se pelo diferencial de uso do solo urbano, que está relacionado às ações dos distintos atores que se apropriam desta. $\mathrm{O}$ acesso aos bens e infraestrutura urbana se limita a uma pequena parcela da população. Portanto, por meio deste artigo, nos dedicamos a realizar uma abordagem crítica da realidade urbana, no que tange às políticas habitacionais introduzidas no município de Imperatriz-MA. Trata-se de uma análise realizada no conjunto habitacional Itamar Guará I.

No espaço urbano aqueles que possuem mais recursos econômicos paga pelo uso do solo de áreas privilegiadas. Em contrapartida, a maior parcela da população, sofre com a exclusão social e segregação socioespacial. A cidade de Imperatriz, desde a década de 1950 tem expandido de forma horizontal e vertical. Estudos realizados por Sousa (2009); (2013); (2015) e (2018) enfatizam que este crescimento não tem acompanhado melhorias em infraestrutura urbana. As áreas centrais da cidade tornaram-se preenchidas, contribuindo para o processo de verticalização, sobre isto, Oliveira (2017); (2018) destaca que o processo de verticalização presente em Imperatriz ocorre como resultado do esgotamento de espaço nas áreas centrais da cidade. Portanto, em razão desse fato, o centro da cidade não possui espaço para construção de habitações de modo a contemplar segmentos de baixo e médio poder aquisitivo.

É reconhecido que a ausência do planejamento urbano enquanto um dos elementos presente na dinâmica urbana brasileira, tem gerado o afastamento das pessoas mais carentes de recursos econômicos, para áreas cada vez mais distantes dos espaços centrais, especialmente, para lugares onde não há infraestrutura urbana de qualidade, reforçando dessa maneira, a problemática da segregação socioespacial urbana.

Assim sendo, o presente estudo pondera e questiona os significados e efeitos das políticas habitacionais como um dos importantes componentes da produção do espaço urbano, tendo como recorte espacial analítico o conjunto habitacional Itamar Guará I, que foi entregue à população de Imperatriz-MA no ano de 2012, por meio da política conduzida pelo Programa Minha Casa Minha Vida - PMCMV.

\section{NATUREZA E SIGNIFICADOS DA POLÍTICA HABITACIONAL NO BRASIL: entre avanços e retrocessos}

Conjuntos habitacionais como o deste estudo, têm sido implantados a partir da década de 1960, ao longo da evolução do processo de urbanização brasileiro. Embora apresentem as suas especificidades, conforme a política habitacional executada, o intuito se volta a sanar ou atenuar o déficit habitacional apresentado no país, que se expandiu a partir do advento das atividades industriais introduzidas no território. 
A partir de 1950, o processo de urbanização brasileiro se intensificou, tendo como marcas o caráter célere e desordenado. Até 1940, a maior parcela da população brasileira se concentrava em áreas rurais, segundo Maricato (2001, p.66) “em 1940, a população urbana brasileira era de 26,3\%. Já em 2010, essa população passou para 84,4\%. De forma absoluta, nota-se que em 1940, 18,8 milhões de habitantes residiam em áreas urbanas. Em 2010, esta população saltou para 160 milhões". A indústria no país é um dos pivôs do crescimento da malha urbana, com base nesse fato, Silva e Sousa $(2018$, p.5) destacam que "em um curto espaço de tempo, os centros urbanos brasileiros passaram a abrigar mais de 125 milhões de pessoas".

Em razão desse ritmo frenético de crescimento da população urbana no Brasil, as cidades passaram cada vez mais a apresentar problemas relativos ao déficit habitacional. Desse modo, é necessário reconhecer as políticas habitacionais enquanto conteúdos intrínsecos ao processo de urbanização. A partir da intensificação do processo de urbanização brasileiro, após 1950, problemas relativos à moradia se agravaram no país, em particular, o déficit habitacional. Nesse sentido, a Tabela 1 destaca os índices de déficit habitacional presente nas regiões brasileiras nos anos de 2000 e 2015.

Tabela 1. Evolução do déficit habitacional brasileiro por regiões (2000-2015). FONTE: Fundação João Pinheiro (2019). Organização: Autores, 2019.

\begin{tabular}{ccccccc}
\hline Regiões & $\begin{array}{c}\text { Déficit hab. } \\
(\mathbf{2 0 0 0 )}\end{array}$ & \% Total & $\begin{array}{c}\text { Urbano } \\
(\mathbf{2 0 0 0 )}\end{array}$ & $\begin{array}{c}\text { Déficit hab. } \\
\mathbf{( 2 0 1 5 )}\end{array}$ & \% Total & $\begin{array}{c}\text { Urbano } \\
(\mathbf{2 0 1 5 )}\end{array}$ \\
\hline Sudeste & 2.341 .698 & 32,42 & 2.162 .187 & 2.482 .855 & 39,07 & 2.435 .307 \\
Nordeste & 2.851 .197 & 39,48 & 1.811 .553 & 1.971 .856 & 31,02 & 1.442 .690 \\
Sul & 678.879 & 9,40 & 565.217 & 734.115 & 11,55 & 684.502 \\
Norte & 848.696 & 11,75 & 506.671 & 645.537 & 10,16 & 504.966 \\
$\begin{array}{c}\text { Centro- } \\
\text { Oeste }\end{array}$ & 502.175 & 6,95 & 424.223 & 521.381 & 8,2 & 505.235 \\
Brasil & $\mathbf{7 . 2 2 2 . 6 4 5}$ & $\mathbf{1 0 0}$ & $\mathbf{5 . 4 6 9 . 8 5 1}$ & $\mathbf{6 . 3 5 5 . 7 4 4}$ & $\mathbf{1 0 0}$ & $\mathbf{5 . 5 7 2 . 7 0 0}$ \\
\hline
\end{tabular}

Com base nos dados expostos na tabela 1, nota-se que o déficit habitacional no Brasil, apesar do quantitativo ainda ser expressivo, vem diminuindo, denotando uma tímida redução de 6,38\%. No ano 2000, as populações concentradas no déficit habitacional representavam 7.222.645. No tocante às regiões, o Nordeste contou com $39,48 \%$ desse total, superando a região Sudeste que no período detinha 32,42\% desse quantitativo. Cabe destacar, que em 2000 o déficit habitacional em áreas urbanas do país expressava 75,73\%, reforçando o descaso com a moradia.

Já no ano de 2015, o déficit da região nordeste foi reduzido para 31,2\%, expressando uma redução de 8,46\%. Enquanto isso, a região Sudeste apresentou crescimento de 6,65\%, culminando em 39,07\% do déficit habitacional do país. Se comparado o déficit das áreas urbanas nos respectivos períodos, observa-se que houve um aumento de 0,93\%. Do ponto de vista relativo, a variação percentual de redução do déficit habitacional brasileiro no período pesquisado (2000-2015) equivaleu a 6,38\%. Nesse cenário, podemos observar ainda que a região Sudeste 
apresentou destaque no contexto nacional, com uma participação absoluta de 2.482 .855 de habitantes sem condições de moradias, correspondendo a um percentual de 39,07\% do total brasileiro em 2015.

A região Nordeste por concentrar a segunda maior população do país, também retrata ausência de planejamento que se expressa por meio da falta de moradias, denotando assim, uma série de problemas. Apresentamos a seguir, algumas medidas adotadas pelo Estado brasileiro com relação a produção de moradia, tomando como referência a década de 1960, é neste período que as ações do Estado se tornaram mais visíveis.

\section{CARACTERÍSTICAS DAS POLÍTICAS DE HABITAÇÃO NO PERÍODO DITATORIAL - (1964/1985)}

A partir de 1964 instaurou-se o regime militar no país. O Estado autoritário ao assumir o poder trouxe consigo inovações e o desejo de desenvolver as políticas de habitação no país. No conjunto de medidas adotadas destacase de início a implantação do Banco Nacional de Habitação (BNH). Com a criação do BNH as questões relacionadas ao déficit habitacional passaram a ter maior visibilidade, surgindo o Fundo de Garantia de Tempo de Serviço (FGTS) e o Sistema Brasileiro de Poupança e Empréstimo (SBPE) que deram novos significados para o investimento habitacional.

\footnotetext{
O modelo de política habitacional implementado a partir de 1964, pelo Banco Nacional de Habitação $(\mathrm{BNH})$, baseava-se em características que deixaram marcas importantes na estrutura institucional e na concepção dominante de política habitacional nos anos que se seguiram. Essas características podem ser identificadas a partir da criação de um sistema de financiamento que permitiu a captação de recursos específicos e subsidiados, o Fundo de Garantia de Tempo de Serviço (FGTS) e o Sistema Brasileiro de Poupança e Empréstimo (SBPE), que chegaram a atingir um montante bastante significativo para o investimento habitacional. (MINISTÉRIO DAS CIDADES, 2004, p.9)
}

Ainda neste período foi criado o Sistema Financeiro de Habitação (SFH). Nesse sentido, o financiamento imobiliário tornou-se uma verdadeira alternativa para conter o déficit habitacional. Tanto o BNH quanto o SFH tinham como principal característica possibilitar o financiamento da casa própria, oferecendo incentivos à construção de habitações e possibilidades de amenizar a falta de moradia no Brasil (GOMES, 2016).

Porém, os projetos que foram implantados durante o regime militar ficaram marcados pela falta de compromisso com as populações que vivem à margem da sociedade, ou seja, apresentaram-se como promessas não alcançadas, fomentado ainda mais as desigualdades sociais. Essas medidas resultaram na crise do SFH e na falência do BNH em novembro de 1986, decretado pelo então presidente José Sarney, transferindo as funções do BNH para a Caixa Econômica Federal (GOMES, 2016).

Este período que corresponde à implantação do BNH e SFN, delineado entre as décadas de 1964 até 1986 foi marcado pela defesa dos interesses capitalistas, valorizando o acúmulo de capital a partir de ações concentradoras e excludentes, deixando de lado o viés social da produção do espaço urbano. Portanto, caracterizar o espaço urbano por intencionalidades e especulações, reforça a ideia de segregação do espaço. A lógica de 
produção do espaço urbano alimenta o movimento de constante especulação, seguindo as regras do sistema capitalista, construindo, portanto, novas configurações espaciais, como é o caso dos loteamentos e condomínios fechados (SILVEIRA, 2016).

Com o fim do regime ditatorial em 1985, o SFH passou por uma grave crise, que se agravou com a extinção do BNH. As políticas habitacionais conheceram imobilismo por parte do Estado. Houve "um hiato em relação as políticas habitacionais no país, com a desarticulação progressiva da instância federal" (MINISTÉRIO DAS CIDADES, 2004).

Azevedo (1988, p. 116) ressalta que "apesar da grandiosa quantidade de unidades financiadas pelo BNH nos seus 22 anos de existência - quase 4,5 milhões [...] Entre as unidades financiadas pelo BNH, apenas 33,5 \% foram destinadas aos setores populares".

Com a extinção do BNH, as companhias habitacionais estaduais que antes executavam os programas de habitação, perderam a sua autonomia. A partir daí os programas federais delegaram os municípios como protagonistas do processo de construção de habitações populares (CARDOSO e ARAGÃO, 2013).

Em razão do foco deste estudo se pautar nas políticas contemporâneas, observou-se que no período que corresponde ao final da década de 1990 até o início do século XXI predominou nas políticas habitacionais uma desmobilização do Estado no tocante à questão da moradia. Desse modo, o acúmulo de capital tem ganhado forças nesse debate, reforçando a ideia da produção massiva de casas sem oferecer dignidade às construções.

Somente no século XXI é que o Estado passou a refletir e atuar com maior compromisso a respeito das políticas habitacionais. No entanto, ainda nota-se que há um grande desinteresse por parte do Estado na execução das políticas habitacionais no país.

\section{PARTICULARIDADES E SIGNIFICADOS DAS POLÍTICAS HABITACIONAIS NA CONTEMPORANEIDADE}

Os processos recentes de reestruturação das políticas de habitação podem ser delineados a partir de 2003, no governo do então presidente Luiz Inácio Lula da Silva. Desde então, foi instituído o Ministério das Cidades, designado para promover condições para articulação das políticas urbanas com a contribuição da sociedade, visando desenvolver a produção sustentável do espaço urbano (GOMES, 2016).

No governo do presidente Lula, houve uma continuidade da organização das políticas habitacionais no que tange ao financiamento de moradias, sendo mantido o uso do FGTS para o financiamento de habitações. Porém, diferente de governos anteriores, a população de baixa renda é apresentada como alvo central dos projetos habitacionais desenvolvidos a partir da universalização do FGTS. 
Ao considerar esse processo de evolução das políticas habitacionais no Brasil, em 2007 ainda no Governo do presidente Lula, foi lançado o Programa de Aceleração do Crescimento (PAC) que se refletiu na produção de moradias, para Cardoso e Aragão (2013, p.33) “a partir de 2005, o mercado imobiliário habitacional experimenta uma fase de crescimento constante, com a ampliação da produção e crescimento dos preços, configurando um 'boom' imobiliário no Brasil".

O governo propôs por meio do PAC, impulsionar a economia brasileira intentando envolver o caráter social, a fim de desenvolver ações através de três eixos: infraestrutura na mobilidade (aeroportos, rodovias e hidrovias), energia (geração de energia elétrica e transmissão e combustíveis naturais e renováveis) e questões sociais e urbanas (saneamento básico, mobilidade urbana e habitação).

\section{PROGRAMA MINHA CASA MINHA VIDA: uma breve caracterização}

No ano de 2009 com vistas de combater a crise global desencadeada nos Estados Unidos foi introduzido no país, por meio do PAC, o Programa Minha Casa Minha Vida - PMCMV, que teve por objetivo central a produção de moradias para populações de diferentes extratos sociais, em particular, baixa renda, reforçando assim o caráter social do programa. Para Cardoso e Aragão (2013, p.21) buscou-se "estabelecer um patamar de subsídio direto, proporcional à renda das famílias, visando claramente impactar a economia através dos efeitos multiplicadores gerados pela indústria da construção civil".

O PMCMV encontra-se subdividido em quatro faixas e para cada faixa há um público particular. A faixa 1 destina-se às populações que dispõem de renda mensal de até $\mathrm{R} \$ 1$ 1.800,00 (Hum mil e oitocentos reais). A faixa 1,5 por sua vez, é destinada às populações que apresentam renda mensal de até $R \$ \$ 2.600,00$ (Dois mil e seiscentos reais). A faixa 2 se volta às populações cujos rendimentos salariais alcançam até $R \$ 4.000,00$ (Quatro mil reais) e a faixa 3 é destinada aos que possuem renda mensal de até $\mathrm{R} \$ \mathbf{7 . 0 0 0 , 0 0}$ (Sete mil reais), conforme demonstra a Tabela 2.

Tabela 1. Faixas e exigências salariais do PMCMV - 2020. FONTE: Caixa Econômica Federal (2020), Organização: autor, 2020.

\begin{tabular}{cc}
\hline Faixas de renda & Exigência de salário em $\mathbf{R} \mathbf{S}$ \\
\hline Faixa 1 & Até $1.800,00$ \\
Faixa 1,5 & Até $2.600,00$ \\
Faixa 2 & Até $4.000,00$ \\
Faixa 3 & Até $7.000,00$ \\
\hline
\end{tabular}

O PMCMV buscava estimular o financiamento de habitações para diversas classes sociais, promovendo a ampliação do mercado imobiliário a partir de alianças do Estado e o setor privado, os incorporadores imobiliários 
se ligavam a esse programa como parceiros. Moreira Júnior (2010, p.3) ressalta que "o papel dos incorporadores visa determinar a localização, tamanho e qualidade das moradias a serem construídas".

É reconhecido que o solo urbano nas cidades capitalistas contemporâneas tem agregado valores significativos. Nessa perspectiva, Volochko $(2008$, p.78) aponta que "em primeiro lugar, comparada com outras mercadorias, a produção do espaço urbano mantém relação intrínseca com o poder político do Estado, que atua como instância de normatização, regulamentação e aprovação da produção desta mercadoria".

No caso específico da cidade de Imperatriz, Carvalho (2016), destaca a maneira seletiva em que se apresenta a organização do espaço urbano da cidade, em que paga-se para morar bem àqueles que dispõem de alto poder aquisitivo. Araújo (2017, p.72) complementa estas reflexões ao afirmar que "a lógica capitalista de produção do espaço urbano não é para todos, a moradia, portanto, apresenta-se como mercadoria de difícil acesso para a classe trabalhadora".

No âmbito do PMCMV, a provisão das habitações populares é marcada pelas intenções das grandes empresas imobiliárias. Como o solo urbano nas áreas centrais das cidades é mais caro, a opção é a procura por áreas cada vez mais afastadas dos centros urbanos, onde o valor pago pela terra é mais barato. Nesse sentido, a segregação socioespacial emerge como problemática central deste processo.

REPRODUÇÃO DO ESPAÇO URBANO EM IMPERATRIZ-MA: a segregação socioespacial como traço característico

A segregação socioespacial presente no espaço urbano apresenta distintos significados, uma vez que considera as distintas formas de organização da sociedade neste espaço. Corrêa (1989) entende a segregação socioespacial a partir de múltiplos significados. Neste particular, interessa discuti-la a partir do contexto residencial, mesmo sabendo que esta perspectiva se apresenta como incompleta no contexto da realidade urbana contemporânea. Trata, pois, de um ponto de partida para entender as faces da política habitacional contemporânea materializada em Imperatriz.

A segregação é gerada a partir das contradições do processo de apropriação do espaço urbano, portanto, os espaços dão identidade para cada grupo social. Vasconcelos (2004, p. 260), por seu turno, conceitua a segregação a partir das origens da palavra, advindas do latim segrego, denotando "separar do rebanho, isolar, dicotomizar". Ao empregar essa terminologia aos estudos urbanos buscamos compreendê-la em seu sentido amplo, reconhecendo a cidade como um produto da sociedade que reflete processos desiguais de apropriação, ou seja, que é negada a muitos sujeitos. 
Reconhecemos que há diferentes perspectivas teóricas acerca do conceito de segregação socioespacial urbana. Desse modo, corrobora-se da ideia de que este conceito em sua essência é polissêmico. Nessa perspectiva, Frey e Duarte (2006, p.110) enfatizam que "a segregação socioespacial é comumente analisada como indicativo de agrupamentos humanos, desfavorecidos no âmbito de um conjunto social - seja por questões raciais, religiosas ou econômicas, esta última com especial destaque no Brasil”.

Logo, com base no objeto deste estudo, considera-se que, assim como apontam Frey e Duarte (2006) as questões socioeconômicas se apresentam como elementos vitais que confirmam a segregação socioespacial presente no espaço urbano de Imperatriz. Assim sendo, compreende-se que as questões socioeconômicas se apresentam como o muro e a porta para o acesso e saída à cidade e aos bens materializados nesta.

Dito isto, reconhecemos que as populações que detêm alto poder aquisitivo conseguem ter o poder de escolha de suas moradias, ou seja, a localização que envolve o acesso aos serviços de educação, saúde, segurança, bem-estar ambiental, espaços de lazer, áreas verdes, e todos os elementos que envolvem infraestrutura urbana adequada. Porém, diferentes sujeitos, sobretudo as populações de baixo poder aquisitivo, que estão sujeitas ao jogo de interesses do capital imobiliário e sob a submissão do Estado, não usufruem desse aparato. Esse jogo denota traços excludentes, criando barreiras que são mais resistentes do que qualquer muralha, negando assim o direito à cidade com infraestrutura adequada que é devido a todo cidadão.

Nessa lógica que é guiada pelo capital imobiliário, a segregação socioespacial se afirma. Desse modo, Negri (2008, p.148) entende a segregação como "um fenômeno espacial, e não como um mero reflexo das diferenças sociais, mas um espaço que é organizado de acordo com os interesses das diferentes classes".

Acredita-se que a segregação urbana se configura a partir do uso distinto e segmentado do solo urbano, esse uso nem sempre é sinônimo de exclusão das populações. Pode-se pensar a segregação difundida em uma mesma área, abrigando populações de alto e baixo poder aquisitivo, configurando processos de autosegregação. No entanto, mesmo reunidas numa mesma área, os conteúdos e padrões de moradia revelam o caráter distinto e segmentado de apropriação do espaço urbano.

Observa-se que a cidade capitalista visa produzir espaços desiguais. No caso da cidade de Imperatriz, Oliveira (2017), ressalta os estreitos vínculos da segregação urbana com o atual processo de verticalização da cidade.

Os grandes edifícios estão cercados por populações que vivem à margem da sociedade. Nesse sentido, como ilustrado nas Figuras 01 e 02, a segregação pode ser identificada em uma mesma área, de um lado apresenta-se o resultado da construção de um grande edifício na cidade (Quinta Avenida) situado em um bairro da área central. Limítrofe a este bairro central, situa-se o Bairro da Caema que apresenta infraestrutura com condições precárias, revelando assim os conteúdos desiguais da urbanização. 
Figura 1. Edifício Quinta Avenida. Fonte: Autores, 2019

Figura 2. Bairro da Caema. Fonte: Autores, 2019
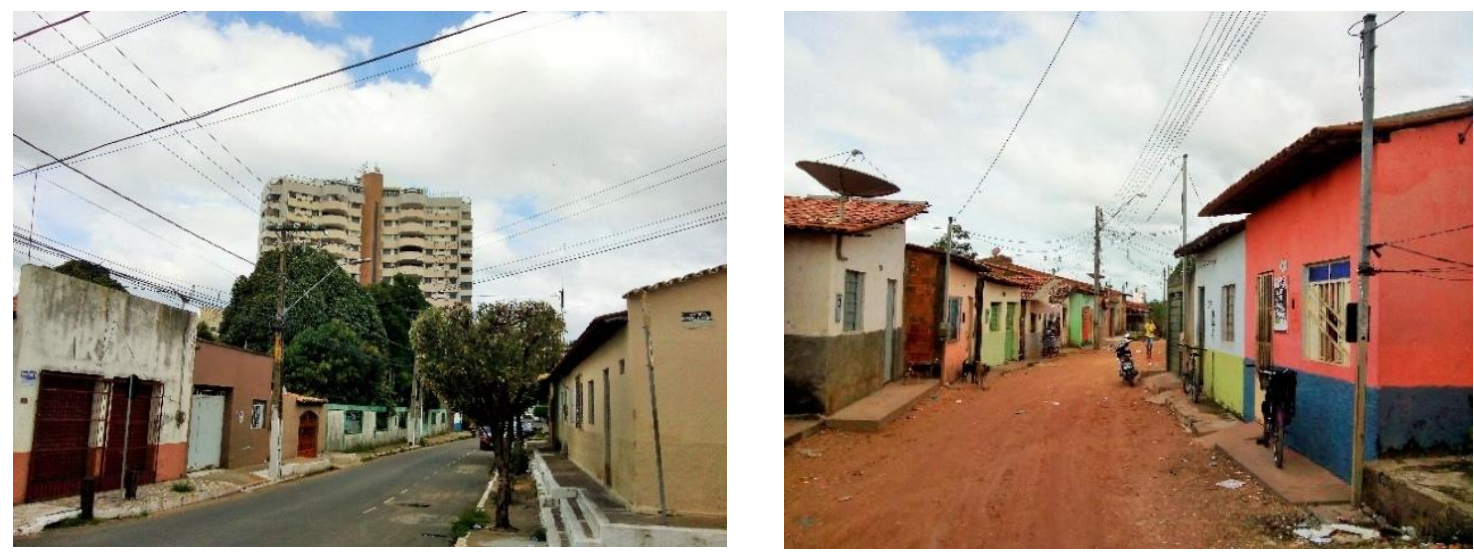

Ao observar as imagens anteriores, cabe

indagarmos quem produz a segregação socioespacial urbana? Em sua obra, "O espaço urbano", Corrêa (1989) enfatiza os agentes que produzem a segregação. São eles: o Estado, os incorporadores imobiliários, os proprietários dos meios de produção, os proprietários fundiários e os grupos sociais excluídos. Segundo Corrêa (1989, p.64) "em realidade pode-se falar em auto-segregação e segregação imposta, a primeira referindo a segregação da classe dominante e a segunda a dos grupos sociais cujas opções de como e onde morar são pequenas ou nulas".

Nota-se que os grupos sociais excluídos sofrem com a reestruturação do espaço urbano, apresentando-se como objeto manipulado pela classe dominante, onde se inserem os incorporadores imobiliários. Assim, a segregação socioespacial analisada a partir do diferencial de uso do solo urbano é marcada pela ação e interesses dos agentes que detêm o poder na cidade. Ao levar em conta a atuação desses agentes, destacamos a questão da moradia, por meio da política habitacional difundida na cidade de Imperatriz.

O processo de evolução das políticas habitacionais no Brasil é reconhecido através de interesses diversos, uma vez que envolve distintos agentes. Os incorporadores imobiliários com a anuência do Estado se mostram como principal produtor do espaço urbano, produzindo a segregação socioespacial. Essa é característica do Programa Minha Casa Minha vida - PMCMV que apesar de ter se desenvolvido em um governo considerado de esquerda, ainda assim tem apresentado características excludentes e segregadoras.

[...] o programa apresenta, desde sua concepção, duas contradições básicas que se articulam. Uma primeira contradição ocorre entre os objetivos de combater a crise, estimulando a economia, e os objetivos de combater o déficit habitacional; uma segunda, decorrente do privilégio concedido ao setor privado como agente fundamental para efetivar a produção habitacional, deixando de lado, ou em segundo plano, outras alternativas de produção baseadas na produção pública ou na autogestão, coletiva ou individual (CARDOSO e ARAGÃO, 2013, p.44).

Para entender os efeitos da política habitacional desenvolvida na cidade de Imperatriz é que propomos analisar por meio deste estudo os seus desdobramentos, questionando as intervenções dos distintos sujeitos que se fazem presentes no conjunto habitacional Itamar Guará I. 
A cidade de Imperatriz tem crescido de forma significativa o seu tecido urbano. O núcleo central da cidade tornou-se preenchido, denotando dispor de parcos espaços vazios, ou seja, vazios urbanos. A respeito do processo de urbanização que é peculiar à cidade de Imperartiz, Silva e Sousa (2018) destacam a influência da construção da rodovia Belém-Brasília e a centralidade exercida pelo setor terciário que se consolidou a partir de 1980, sendo esses os propulsores do processo de urbanização de Imperatriz.

Os principais vetores da expansão urbana da cidade de Imperatriz se direcionam para as porções leste e nordeste da cidade. No entanto, há outras áreas que têm despertado os interesses do mercado imobiliário, este fato é confirmado pelos estudos realizados por Sousa (2015, p. 372), que enfatiza "a expansão da malha urbana em Imperatriz, a partir de 1980 avança para áreas antes não alcançadas, como é o caso do sentido norte-sul, onde havia os limites naturais, ultrapassando os riachos Cacau e Bacuri".

O objeto de estudo em foco destaca a área situada na porção Sul da cidade de Imperatriz, que é reconhecida no cenário contemporâneo de urbanização como um dos vetores da sua expansão urbana. Trata-se do Conjunto Habitacional Itamar Guará I, situado às margens da BR - 010 e a Ferrovia Norte Sul numa área periférica desta cidade. A Figura 3 expõe a localização desse conjunto.

Figura 3. Localização do Conjunto Habitacional Itamar Guará I, 2020.

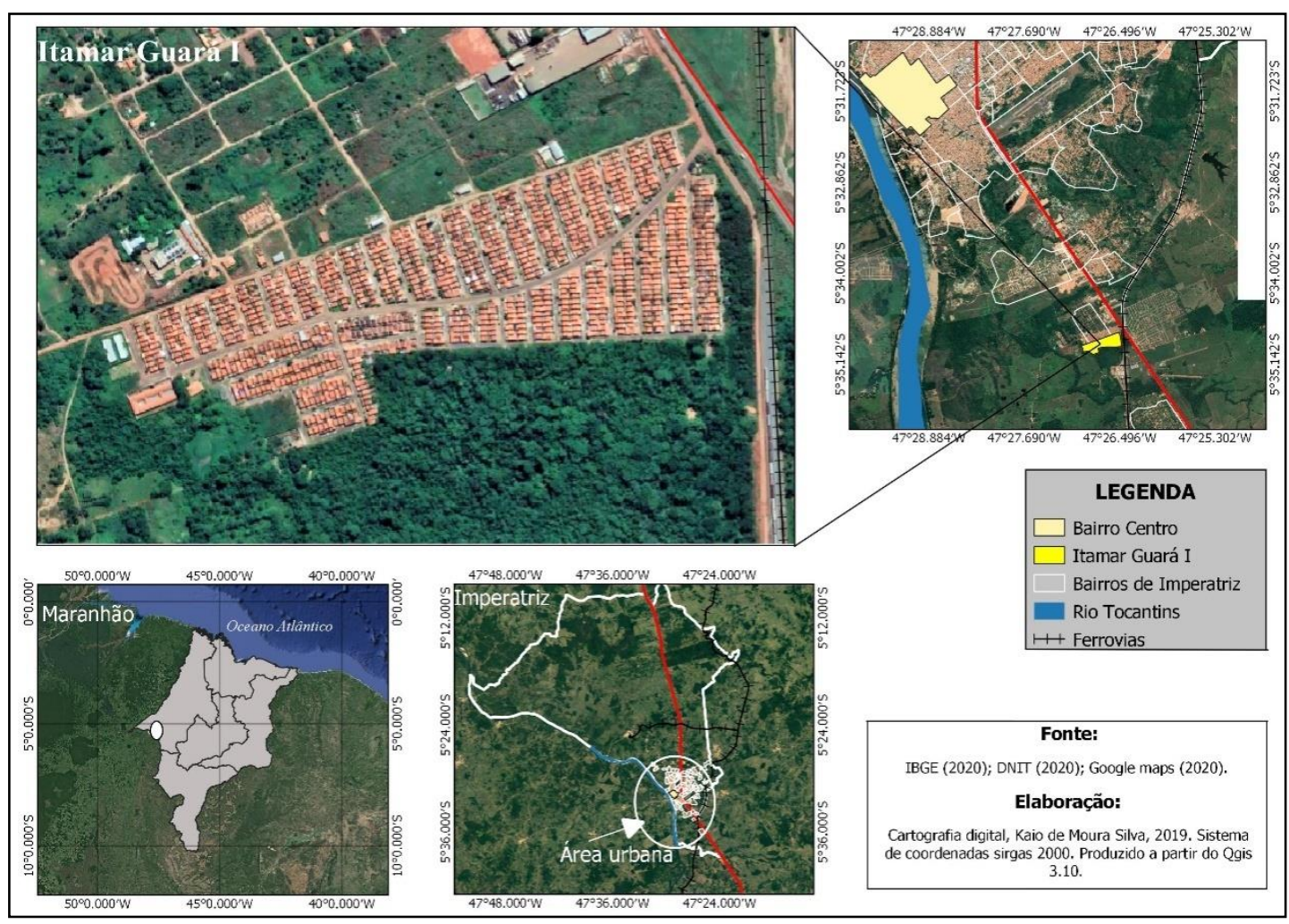


Com base nas ideias expostas, observa-se que as políticas habitacionais difundidas na realidade urbana brasileira são marcadas por promessas e planos que intentaram atenuar e até mesmo solucionar as carências sociais das populações em suas cidades.

No entanto, ao refletir sobre a evolução das políticas habitacionais no Brasil, nota-se o caráter excludente dos programas e, consequentemente, as ações governamentais, considerando que os problemas que envolvem a habitação no Brasil não se expressam apenas por meio do déficit habitacional, eles vão além, pois envolvem a infraestrutura urbana, como é o caso da ausência de saneamento básico (rede de abastecimento de água e esgoto), ausência de áreas verdes e de áreas de lazer, entre outros.

Com vistas de apreender os significados destas políticas executadas em Imperatriz, optou-se por realizar esta investigação, considerando a realidade vivenciada pelas populações residentes no Conjunto Habitacional Itamar Guará I (Figura 4)

Figura 4. Conjunto habitacional Itamar Guará I visto da rodovia Belém-Brasília. FONTE: Autores, 2018.

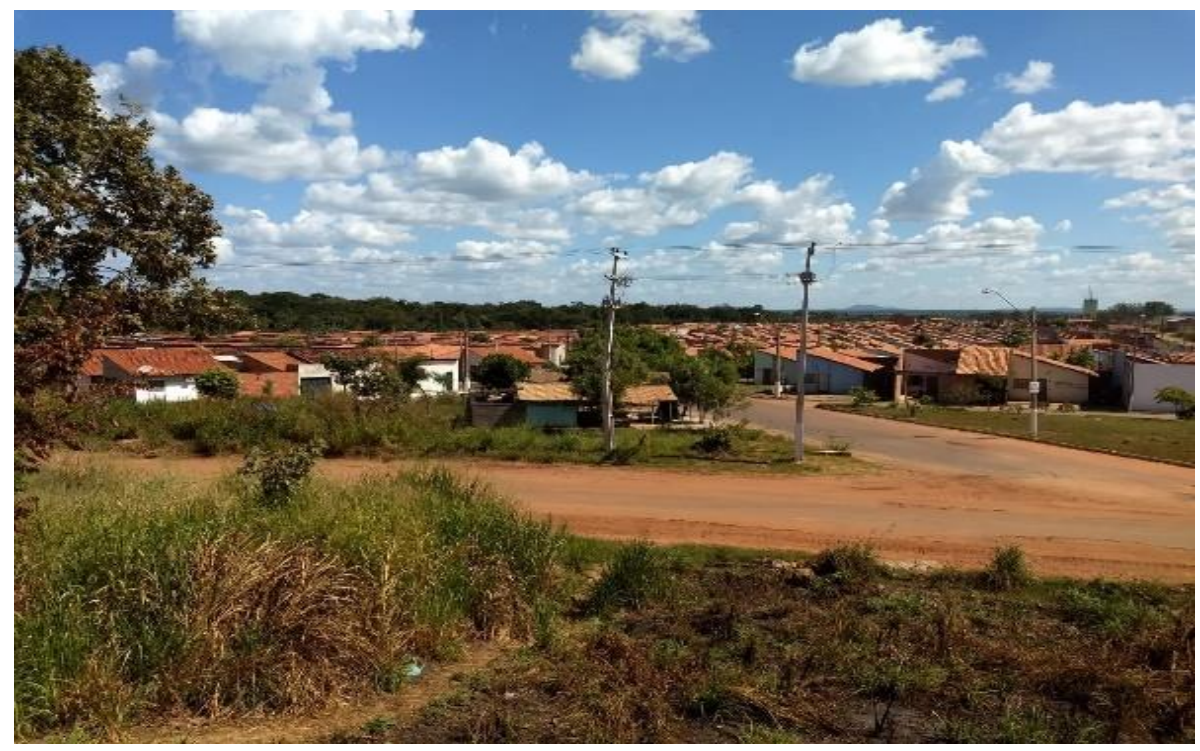

Desse modo, apresentamos a seguir alguns dos resultados que foram obtidos por meio da pesquisa empírica que se realizou no mês de setembro e outubro de 2018. Antes disso, é importante apresentarmos a metodologia usada nesta investigação.

\section{PROCEDIMENTOS METODOLÓGICOS DA PESQUISA}


Os estudos de natureza científica devem se fundamentar em instrumentais metodológicos que sejam condizentes com a problemática destes e com as finalidades delineadas para a investigação. Desse modo, ressalta-se a seguir os principais instrumentos que serviram de base ao desenvolvimento desta pesquisa.

Este estudo, apoia-se na adoção da abordagem marxista. Segundo Triviños (1987, p.49), “o marxismo compreende, três aspectos principais: o materialismo dialético, o materialismo histórico e a economia política". O espaço urbano constrói-se de forma muito desigual, ou seja, contraditória. Portanto, é relevante interpretarmos de forma totalizante esta realidade em Imperatriz a partir dos aspectos contraditórios presentes no espaço urbano.

Nesse sentido, o método dialético é o mais pertinente para esta investigação, pois como notou Gil (2008, p.14) “a dialética fornece as bases para uma interpretação dinâmica e totalizante da realidade, já que estabelece que os fatos sociais não podem ser entendidos isolados e abstraídos de suas influências políticas, econômicas, culturais etc."

No que concerne às técnicas de pesquisa, trabalhamos com a observação simples que é a técnica de pesquisa que possibilita ao investigador uma série de vantagens, dentre elas: a obtenção de elementos para definição de problema e favorece a construção de ideias com base no problema estudado. A observação simples, segundo Gil (2008, p. 101), “é aquela em que o pesquisador, permanecendo alheio à comunidade, grupo ou situação que pretende estudar, observa de maneira espontânea os fatos que aí ocorrem. Neste procedimento, o pesquisador é muito mais um espectador que um ator".

Optou-se por trabalhar ainda com entrevistas semiestruturadas. Segundo Triviños (1987, p.146) entrevista semiestruturada é "[...] aquela que parte de questionamentos básicos, apoiados em teorias e hipóteses, que interessam a pesquisa e que, oferecem amplo campo de interrogativas, fruto de novas hipóteses que vão surgindo à medida que se recebem as respostas do informante". Assim sendo, com a entrevista semiestruturada buscamos compreender e analisar a percepção que os moradores têm de suas moradias no conjunto habitacional Itamar Guará I.

Ainda relacionado aos aspectos metodológicos utilizados nesta investigação, ressalta-se a adoção da abordagem qualitativa. Conforme Chizzoti (2003):

Tomam formas textuais originais, recorrendo a todos os recursos linguísticos, sejam estilísticos, semióticos ou diferentes gêneros literários, como conto, narrativas, relatos, memórias; recursos estilísticos diferenciados permitem apresentar de forma inovadora os resultados de investigações, criando um excitante universo de possibilidades (CHIZZOTTI, 2003, p.222).

A metodologia apresentada proporcionou melhor compreensão da problemática abordada neste estudo. A realidade urbana da cidade capitalista contemporânea apresenta-se de maneira contraditória, as 
políticas habitacionais enquanto conteúdo inerente à produção do espaço urbano se apresenta de maneira segmentada e dual, alimentando o sentido excludente do sistema capitalista. Portanto, esta metodologia mostrou-se extremamente importante para o desenvolvimento deste estudo.

\section{EXPRESSÕES DAS POLÍTICAS HABITACIONAIS DIFUNDIDAS EM IMPERATRIZ-MA: uma abordagem do conjunto habitacional Itamar Guará I}

O conjunto habitacional Itamar Guará I foi implantado na cidade de Imperatriz no ano de 2012, contando com 1.000 mil famílias cadastradas e contempladas, destas foi direcionado um roteiro de entrevista que alcançou 20 famílias. Esta quantidade foi adotada em razão da natureza desta pesquisa, que é amparada no caráter qualitativo.

No conjunto de elementos analisados, levamos em consideração desde a localização do conjunto, a estrutura física das casas, entre outros aspectos, como é o caso das condições de saúde, educação, segurança e mobilidade. Buscamos ouvir e analisar a percepção dos moradores, no que tange às condições de suas moradias, sendo fundamental para a compreensão da política de habitação desenvolvida nesta localidade. O roteiro de entrevista apresentado aos moradores foi sistematizado, considerando três blocos distintos.

O primeiro bloco se propôs a identificar o perfil socioeconômico dos moradores do conjunto habitacional Itamar Guará I. Neste quesito foram questionados:

- A média de idade e o rendimento médio salarial, bem como a profissão do responsável da família e sua escolaridade.

No segundo bloco foi questionado aos moradores, a percepção que estes têm no que tange às condições das moradias do conjunto. Foram apresentadas neste quesito as seguintes indagações:

- Está satisfeito com a moradia no Conjunto Itamar Guará I?

- O conjunto habitacional oferece condições adequadas de infraestrutura urbana?

- Quais os impactos (aspectos positivos e negativos) ao adquirir a casa própria?

As respostas dos moradores estão expostas a seguir, considerando os dois primeiros blocos de indagações. Segue-se as vozes dos sujeitos:

Tenho 43 anos, trabalho de pedreiro. A minha média salarial mensal é de um salário mínimo e não terminei o ensino fundamental. As coisas aqui são muito difíceis, questão do acesso ao mercado e outras coisas que são muito ruins. O conjunto não oferece condições adequadas de saneamento básico. 
Porém, sair do aluguel foi um impacto positivo para a minha vida, apesar do conjunto não dispor de boas condições de saúde. (Morador $1^{1}$, entrevista realizada em 15/09/2018)

Tenho 35 anos. Sou comerciante e tenho renda mensal acima de 3 salários mínimos. Tenho o ensino médio completo. Eu estou satisfeito com minha moradia no Conjunto. É bem localizada e o lugar aonde eu trabalho é de fácil acesso. Tenho isso como ponto positivo. Infelizmente o Conjunto não dispõe de bom saneamento básico, quando chove as tubulações de esgoto entopem e as casas ficam alagadas. Esse é um ponto negativo. (Morador 2, entrevista realizada em 15/09/2018)

Tenho 25 anos, sou mecânico e a minha renda mensal é em torno de um salário mínimo e não conclui o ensino fundamental. Não estou satisfeito com a moradia aqui no conjunto, porque a distribuição de água não é boa. $O$ conjunto não oferece condições adequadas de saneamento básico. $O$ esgoto não funciona e quando chove os bueiros estouram e invadem as casas, esse é um aspecto negativo. Sair do aluguel foi um ponto positivo. (Morador 3 , entrevista realizada em 15/09/2018)

Com base nas vozes expostas, nota-se que os moradores entrevistados apresentam idade entre 20 e 45 anos, estando incluídos na faixa etária adulta, ou seja, se inserem na faixa etária da população economicamente ativa. Segundo Dedecca e Ferreira (1989, p. 79) "a população economicamente ativa corresponde à parcela da população em idade de trabalhar que se encontra no mercado de trabalho, seja na condição de ocupado, seja na de desempregado".

No quesito perfil socioeconômico dos moradores, destacamos o processo de formação desses sujeitos, reconhecemos que a maioria dos chefes de famílias entrevistados não concluíram a educação básica e se inserem no grupo das populações que apenas reproduzem a mão-de-obra, reforçando os grupos sociais excluídos.

O conjunto Itamar Guará I se enquadra na faixa 1 do PMCMV, contemplando as populações que dispõem de renda mensal média de até 3 salários mínimos. Em conformidade com as entrevistas realizadas, nota-se que suas profissões não têm prestígio social, pelo fato de serem profissões que não exigem, em via de regra, qualificação adequada, um curso técnico ou superior, por exemplo. Muitos dos entrevistados destacam como sendo suas profissões: mecânico, pedreiro, carpinteiro, entre outros.

No tocante à produção de moradias, conforme as vozes expressas pelos entrevistados, entende-se que parcela significativa destes se sentem realizados com as suas moradias, mesmo apresentando problemas, para eles, este fato por si só é vantajoso. No entanto, reconhecemos que de nada adianta apenas distribuir casas e promover políticas públicas sem assegurar dignidade na produção dessas moradias.

Nesse sentido, há contradições no que diz respeito às propostas desenvolvidas pelo Estado no que tange à política habitacional, uma vez que é defendido o sentido amplo de moradia, fundamentado na dignidade desses sujeitos. Estas ideias são corroboradas pelo ministério das cidades, "a política de habitação se inscreve

\footnotetext{
1 Para preservar a identidade dos sujeitos, optamos por identificá-los por: $\mathrm{M}^{1}, \mathrm{M}^{2}$ e $\mathrm{M}^{3}$. Cabe destacar que realizamos um total de 20 (vinte) entrevistas com chefes de famílias e responsáveis. Destas, optamos por dispor três aqui neste estudo, em razão da natureza qualitativa desta pesquisa.
} 
na concepção de desenvolvimento urbano integrado, no qual a habitação não se restringe a casa, incorpora o direito à infraestrutura, saneamento ambiental, mobilidade e transporte coletivo, equipamentos e serviços urbanos" (MINISTÉRIO DAS CIDADES, 2004, p.12).

Assim sendo, com base nas vozes dos moradores entrevistados no conjunto Itamar Guará I, percebe-se que há um descaso com a infraestrutura urbana, uma vez que existem condições parcas de saneamento básico no conjunto, isto se confirma pelo irregular abastecimento de água e pela precária condição de infraestrutura na rede de esgoto, oferecendo riscos à saúde e à qualidade de vida da população. Essa afirmação é confirmada na voz do morador 2 quando ele fala "infelizmente o conjunto não dispõe de saneamento básico, quando chove as tubulações entopem e as casas ficam alagadas. "

Embora o morador 2 enfatize que o conjunto habitacional Itamar Guará I não dispõe de saneamento básico, mediante as observações, foram identificadas insuficiências nas condições do saneamento básico, ou seja, água com abastecimento irregular (percebido pela fala do morador 3) e a rede de esgoto precária, expressa a partir dos bueiros estourados nas ruas, assim sendo, por dispor de tais condições, o morador 2 acabou sendo redundante em seu comentário.

É importante destacar os aspectos positivos que foram ressaltados pelos moradores, mesmo considerando que eles são praticamente nulos diante dos problemas já expostos. A este respeito, o morador 1 afirma como aspecto positivo que "sair do aluguel foi um impacto positivo para a minha vida, apesar do conjunto não dispor de boas condições de saúde". A aquisição da casa é entendida como um dado positivo, no entanto, não podemos ocultar as marcas da segregação que a política de habitação tem gerado. No caso particular do Conjunto Habitacional Itamar Guará I ela se expressa, por exemplo, em razão da negação, ou seja, a ausência dos equipamentos e infraestrutura no espaço urbano, como serviços de saúde, segurança pública, educação, saneamento básico, áreas de lazer, entre outros, isto é negado aos sujeitos, mesmo sendo direito de todos. Assim sendo,

\footnotetext{
O modo de produção de moradias populares para além dos limites da cidade tem consequências graves que acabam prejudicando a todos. Além de encarecer a extensão das infraestruturas urbanas, que precisam alcançar locais cada vez mais distantes, o afastamento entre locais de trabalho, os equipamentos urbanos e as áreas de moradia aprofundam as segregações socioespaciais e encarecem os custos da mobilidade urbana. (ROLNIK e NAKANO apud CARDOSO e ARAGÃO, 2013, p.48)
}

No terceiro bloco de entrevistas direcionado aos moradores do conjunto habitacional Itamar Guará I, foi questionado como tem se dado a participação do poder público com relação à provisão de equipamentos e serviços urbanos, como é o caso da segurança pública, mobilidade, etc. Foi questionado, também, a respeito da estrutura das casas do conjunto e qual setor eles destacam que deveria melhorar no conjunto. 
Portanto, apresentamos a seguir as indagações e respostas que compreenderam o terceiro bloco de questões apresentado aos moradores/as do conjunto:

- O poder público oferece aos moradores/as segurança pública?

- O conjunto habitacional dispõe de transporte público, você está satisfeito/a?

- A estrutura da casa está de acordo com as suas expectativas? O que deve melhorar no conjunto em termos de infraestrutura?

Apresentamos a seguir as respostas obtidas em razão das entrevistas realizadas com os moradores no que tange ao terceiro bloco de questionamentos:

\begin{abstract}
O conjunto oferece segurança, porque existe ronda policial. Porém, não conta com delegacia, nem posto policial. Dispõe de ônibus, porém, eu não estou satisfeito com os serviços de transporte. Os ônibus não são exclusivos para o conjunto habitacional Itamar Guará. Eles passam pelo conjunto Vitória e pela vila Vitória, para chegarmos até o centro da cidade. As viagens se tornam mais longas e cansativas. A estrutura da casa não está de acordo com minhas expectativas. O material é de péssima qualidade. É péssimo reboco e a cerâmica não é de qualidade. Fui obrigado a recolocar, porque estava soltando tudo. A educação e o saneamento são as principais coisas que devem ter maior cuidado e atenção do governo. O conjunto não tem uma área de lazer, seria importante a construção. Uma delegacia também é fundamental para o conjunto. (Morador 1, entrevista realizada 15/09/2018)

$\mathrm{O}$ conjunto conta com a ronda policial, porém, seria melhor se tivesse um posto policial. O conjunto conta com ônibus e são eficientes. Estou satisfeito com a estrutura da casa. Era o que a gente esperava. O saneamento básico e a segurança são os setores que devem ter mais atenção do governo. Como sugestão para a melhoria do conjunto destaco, a implantação de um posto policial e o tratamento adequado da água que são fundamentais. (Morador 2, entrevista realizada 15/09/2018)

Existe no conjunto a ronda policial frequentemente. O conjunto conta com ônibus com perfeita circulação. A estrutura da casa não está de acordo com as minhas expectativas. Na construção da casa não teve um bom alinhamento. Quando chove, a água acumulada na rua afeta as casas. O saneamento básico e a educação são os setores que precisam de maior atenção no conjunto. A construção de uma creche para as crianças do conjunto é a minha sugestão para a melhoria do conjunto. (Morador 3 , entrevista realizada 15/09/2018)
\end{abstract}

Ao observar as falas dos entrevistados, compreende-se que apesar dos moradores ressaltarem a importância da aquisição de suas casas, há problemas graves, que denotam carências de infraestrutura urbana. O saneamento básico se apresenta como um dos problemas crônicos do conjunto, conforme relatado pelos moradores. Tal fato pôde ser confirmado e está exposto na Figura 5. 
Figura 5. Insuficiência em bueiro de esgoto - Itamar Guará I. FONTE: Autores, 2018.

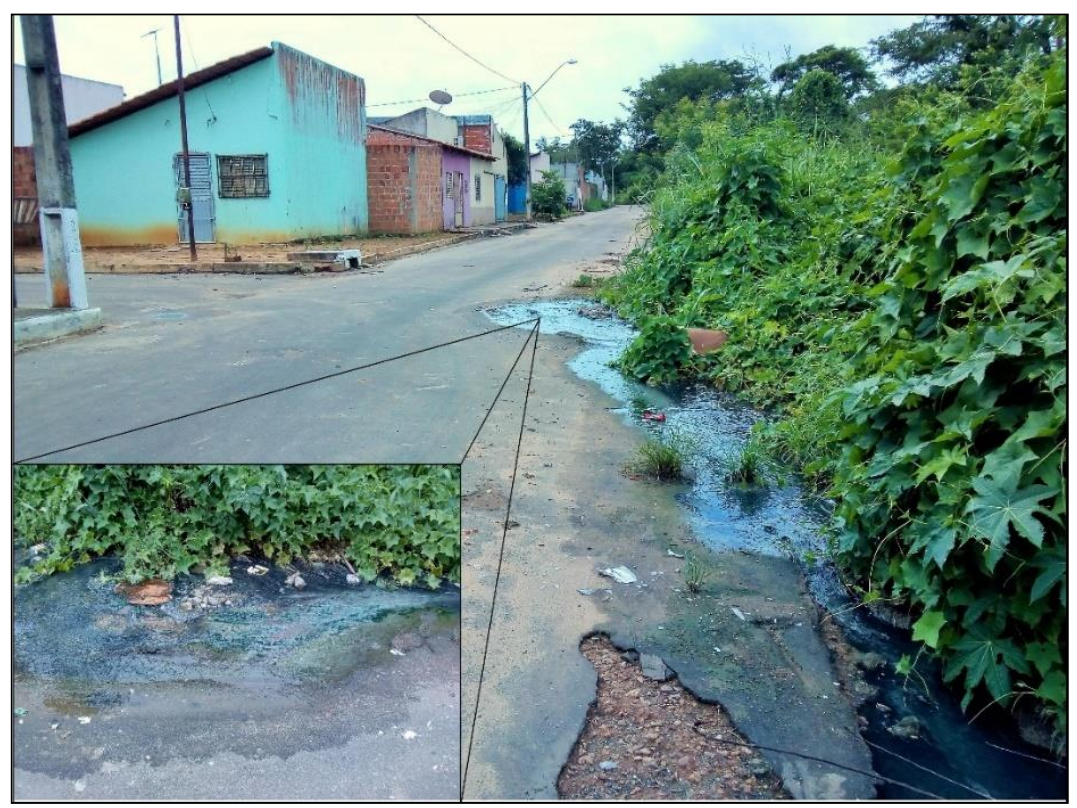

A Figura 5 denuncia o descaso com a infraestrutura no conjunto Itamar Guará I. A parca manifestação do saneamento básico na realidade torna problemas como estes recorrentes no conjunto, haja vista que o serviço de saneamento básico não foi feito a contento. A falta de infraestrutura urbana é um problema encontrado em todas as cidades do país, "a ausência de infraestrutura urbana e saneamento ambiental envolvem 10,2 milhões de moradias, [...] sendo 60,3\% nas faixas de renda de até 3 salários mínimos" (MINISTÉRIO DAS CIDADES, 2004, p. 17).

Esta carência da infraestrutura nas cidades brasileiras constitui um elemento do processo de segregação espacial urbana, segundo Frey e Duarte $(2006$, p.2) "o fenômeno da segregação pode ser visto, como um movimento de exclusão de um grupo de pessoas do seu direito à cidade". Nesse sentido, a segregação socioespacial presente na realidade do Itamar Guará I tem como um dos indicadores a fraca infraestrutura da rede de esgoto, que não supre as necessidades da população.

No entanto, a segregação também pôde ser constatada em razão de diversos outros problemas sociais e ambientais apontados pela população entrevistada. A segregação urbana não separa apenas indivíduos, mas segmenta sonhos, oportunidades, impõem limites que transcendem muros da cidade, Carvalho (2016, p.45) enfatiza que "a materialização espacial das relações sociais revela a segregação, que reflete a desigualdade de condições de apropriação do espaço urbano". O saneamento básico não é o único problema indicado pelos moradores, associada a ausência desses equipamentos urbanos, temos ainda, a ineficiência da segurança pública que contribui para o aumento da violência urbana e para a estigmatização dessa área, bem como a ausência de serviços de educação e saúde. 
Cumpre destacar que o Conjunto Habitacional Itamar Guará I não possui áreas de lazer para a sua comunidade, tais como: praças, campo de futebol, quadra poliesportiva, entre outros. Tal fato corrobora para agravar os problemas sociais nesta localidade, uma vez que sem atividades de lazer, muitos jovens se deparam com atividades ilícitas.

Os moradores enfatizam ainda, a necessidade de investimentos no âmbito da educação, sobretudo, por conta da paralisação da construção de uma creche, que teve início no mandato do então prefeito Sebastião Madeira (2013-2016). As creches são instituições importantes, pois além de contribuírem com o processo inicial de formação das crianças, proporcionam aos pais, oportunidades para exercerem suas funções trabalhistas. Em uma das atividades de campo no conjunto, constatamos que há uma escola municipal, que oferece vagas de séries primárias até os anos finais do ensino fundamental, porém, para estudarem no ensino médio os alunos devem se deslocar para outras áreas/bairros da cidade, aumentando as dificuldades de acesso à educação.

\footnotetext{
Morar num bairro periférico de baixa renda hoje significa muito mais do que apenas ser segregado, significa ter oportunidades desiguais em nível social, econômico, educacional, renda, cultural. Isto quer dizer que um morador de um bairro periférico pobre tem condições mínimas de melhorar socialmente ou economicamente. Implica, na maioria dos casos em apenas reproduzir a força de trabalho disponível para o capital. (NEGRI, 2008, p.136)
}

As características apontadas por Negri (2008) são identificadas no conjunto Itamar Guará I, uma vez que a comunidade não possui saneamento básico eficiente, a água é distribuída irregularmente, não possui áreas destinadas ao lazer e ainda carece de valorização da educação. Estes elementos corroboram com as marcas da segregação neste conjunto. A segregação não apenas separa os sujeitos de áreas periféricas em relação a quem mora em áreas centrais, mas também é capaz de revelar os conteúdos de uma urbanização, que apresenta como principais traços característicos o apartheid social.

Ainda em relação ao âmago dos problemas identificados no conjunto, nota-se a indignação dos moradores com a estrutura de suas casas, haja visto que tiveram que realizar reformas, pois o material era de péssima qualidade, assim, no tocante a estrutura das casas percebeu-se pela fala dos entrevistados, que as expectativas dos moradores não foram contempladas.

No que tange ao transporte público, o conjunto tem boa frequência de ônibus. Quanto aos demais serviços e equipamentos urbanos, percebemos a partir das vozes dos entrevistados, as reivindicações que envolvem a dificuldade de acesso a estes, uma vez que os mesmos apresentam fragilidades em toda a sua estrutura.

Estes fatos corroboram com a ideia de que as políticas habitacionais difundidas na cidade de Imperatriz e, em particular, no conjunto habitacional Itamar Guará I são excludentes e reforçam a segmentação da 
sociedade e uma negação dos direitos dos cidadãos à cidade. Nesse sentido, a segregação socioespacial urbana se afirma como um dos ingredientes, ou seja, como conteúdo da política habitacional orientada a partir do Programa Minha Casa Minha Vida, denotando exclusão social.

\section{CONSIDERAÇÕES FINAIS}

As políticas habitacionais fazem parte da organização do espaço urbano articuladas pelos agentes que moldam o espaço urbano, nesse caso, o Estado, os incorporadores imobiliários, os proprietários dos meios de produção, os proprietários fundiários e os grupos sociais excluídos. A evolução das políticas habitacionais no Brasil tem por marca a construção desigual, dual, excludente e segregadora da cidade, produzindo desigualdades que é traço inerente à cidade capitalista contemporânea.

Percebe-se um avanço em relação à aquisição de moradias, especialmente, a partir da década de 1960, quando se criou um sistema de financiamento de habitação por meio do Banco Nacional de Habitação - BNH, é importante destacar que mesmo com o BNH o caráter excludente prevaleceu. Apenas a partir do desenvolvimento do Programa de Aceleração do Crescimento - PAC no ano de 2007, que as questões que envolvem a habitação passaram a ser mais elaboradas no âmbito social e popular. Em 2009, dentro do PAC, surgiu o Programa Minha Casa Minha Vida que denotou um caráter social das políticas de habitação, construindo moradias para as populações de baixa renda, retratando um sentido de inclusão social, sendo esse o objetivo central do PMCMV, que tornou sua política diferente das desenvolvidas em períodos anteriores.

Porém, essa política apresenta problemas em sua efetivação, pelo fato de não contemplar os direitos essenciais que envolvem a moradia, que é o direito à cidade. Em conformidade com as vozes dos entrevistados do Conjunto Itamar Guará I, observa-se que as falhas do PMCMV são identificadas no referido conjunto habitacional.

A segregação socioespacial presente no Conjunto Itamar Guará I tem como um dos indicadores, a carência nas condições de saneamento básico a partir da ineficiente estrutura da rede de esgoto, a água é distribuída de forma irregular e não apresenta boa qualidade para o consumo. Outro indicador é a condição de segurança pública, haja visto que o conjunto dispõe apenas de ronda policial. No que tange a educação, existe a necessidade da conclusão da obra da creche. Outra carência do conjunto é identificada a partir da inexistência de espaços de lazer. Essa realidade, portanto, revela o sentido polissêmico de segregação socioespacial urbana na contemporaneidade.

Os moradores destacam os problemas ligados ao saneamento básico, uma vez que não há infraestrutura adequada no conjunto. Para tanto, propõe-se que seja expandido (se não criada) uma rede de esgoto, 
sobretudo, criando canais mais profundos para o fluxo dos dejetos, é necessário também a conscientização dos moradores para não jogarem lixos na rua.

No que tange à qualidade da água, os moradores alegam que o problema está na profundidade do poço da comunidade, sendo este muito raso. Portanto, propõe-se que o governo municipal juntamente com a CAEMA (Companhia de Saneamento Ambiental do Maranhão) tome as devidas providências, haja visto que saúde é um direito de todos.

Para o problema da segurança pública, os moradores enfatizam que se sentem seguros apenas com a ronda policial, assim sendo, a intensificação deste serviço (no tocante à frequência) é essencial, sobretudo, pelo quantitativo de mil famílias do conjunto habitacional Itamar Guará I.

Os moradores também reivindicam um espaço de lazer. Deve-se pensar na construção de praças públicas, que apresentem equipamentos de exercícios físicos (academia popular, quadra de areia e ou de futsal). É importante, também, a construção de um campo de futebol, levando em consideração que é um esporte muito praticado no país, para assim, proporcionar aos moradores o sentido de comunidade a partir do direito à cidade.

No que tange a educação, a comunidade necessita da entrega da creche para as crianças do conjunto, a conclusão da obra é fundamental, tanto para o desenvolvimento da criança, quanto para os seus pais terem a oportunidade de trabalhar. O conjunto não dispõe de escola voltada para o ensino médio, seria importante a construção de uma para evitar os descolamentos diários que requerem gastos por partes dos alunos, principalmente, porque estes não possuem ônibus escolar, a escola mais próxima fica a 3 km do Itamar Guará I.

Portanto, propõe-se por meio deste estudo uma política habitacional de inclusão, que leve em consideração os direitos dos cidadãos, com oportunidades iguais para todos, objetivando construir uma sociedade melhor, com menos segregação e mais agregação. A política habitacional deve ter, portanto, características fiéis ao seu discurso, propor na prática a construção inclusiva e qualitativa das moradias.

\section{REFERÊNCIAS}

ARAÚJO, Luciana. Produção imobiliária e novas dinâmicas de expansão urbana em Cajazeiras (PB).2017. 328 f. Tese (Doutorado em Geografia) - Faculdade de Geografia, Universidade Federal da Paraíba, João Pessoa, 2017.

AZEVEDO, Sergio. Vinte e dois anos de política de habitação popular (1964-86): criação, trajetória e extinção do BNH. Revista de Administração Pública, v. 22, n. 4, p. 107-119, 1988.

BRASIL. MINISTÉRIO DAS CIDADES. Política nacional de habitação. Novembro de 2004. Brasília-DF: MCidades/Governo Federal, 2004. 
CARDOSO, Adauto Lucio; ARAGÂO, Thênis. Do fim do BNH ao programa minha casa minha vida: 25 anos da política habitacional no Brasil. In: O programa Minha Casa Minha Vida e seus efeitos territoriais. Rio de Janeiro: Letra Capital,2013. p.16-65.

CARVALHO, Sheryda Lila de Souza. Autossegregação urbana em Imperatriz/MA: um estudo a partir dos condomínios horizontais do bairro Santa Inês. 2016. 207f. Dissertação (Mestrado em Geografia) - faculdade de Geografia, Universidade Federal do Tocantins, Porto Nacional, 2016.

CORRÊA, Roberto Lobato et al. O espaço urbano. Ática, 1989.

CHIZZOTTI, Antonio. Pesquisa em ciências humanas e sociais. Cortez editora, 2003.

DA SILVEIRA, Rogério Leandro Lima. Restruturação Urbana e segregação socioespacial na cidade média de Santa Cruz do Sul- Brasil. Santa Cruz do Sul: Departamento de História e Geografia da UNISC - Brasil, 2016.

DEDECCA, C. S.; FERREIRA, S. P. Transição demográfica e crescimento da população economicamente ativa. São Paulo em Perspectiva, v. 3, n. 3, p. 79-83, 1989.

FUNDAÇÃO JOÃO PINHEIRO. Déficit Habitacional no Brasil. Disponível em: http://fjp.mg.gov.br/index.php/produtos-eservicos1/2742-deficit-habitacional-no-brasil-3. Acessado em: 07/01/2019

FREY, Klaus; DUARTE, Fábio. Auto-segregação e a gestão das cidades. Ciências Sociais em perspectiva, v. 5, n. 9, p. 109-120, 2006.

GIL, Antônio Carlos. Métodos e técnicas de pesquisa social. 1 ed. - 17 reimpr. São Paulo: Atlas, 2008.

GOMES, Cristina. Efeitos da política habitacional no município de Imperatriz - MA:uma avaliação dos avanços e retrocessos do PMCMV no Conjunto Habitacional Itamar Guará I e II. 2016.78 f. Monografia (Graduação em Serviço Social) - Faculdade de Serviço Social. Instituto de Ensino Superior do Sul do Maranhão, Imperatriz/MA, 2016.

IBGE- Instituto Brasileiro de Geografia e Estatística. Cidades. Imperatriz- MA.

Disponívelem: http://www.cidades.ibge.gov.br/xtras/perfil.php?lang=\&codmun=210530\&search=maranhao/imperatriz Acessado em: $28 / 10 / 2018$.

MARICATO, Ermínia. Brasil, cidades: alternativas para a crise urbana. Petrópolis: Vozes, 2001.

MOREIRA JÚNIOR, Orlando. Cidade partida:segregação induzida e auto-segregação urbana. Caminhos de Geografia. Uberlândia, v.13, n. 33, p. 1-10, mar/2010.

NEGRI, Silvio Moisés. Segregação Sócio-Espacial: Alguns Conceitos e Análises.Coletâneas do Nosso Tempo. Rondonópolis - MT. V. VII, nº, p. 129 a 153, 2008.

OLIVEIRA, Helbaneth Macêdo. Verticalização urbana e segregação socioespacial em Imperatriz-MA: uma abordagem a partir dos bairros Jardim Três Poderes e Maranhão Novo. 2017. 204f. Dissertação de mestrado em ciências humanas - Faculdade de Geografia, Universidade Federal do Tocantins, Porto Nacional, 2017.

SILVA, Laila Santos; DE MACEDO SOUSA, Jailson. Novas formas comerciais e as expressões da centralidade urbana de Imperatriz-MA: uma análise a partir da instalação e dinamismo do Imperial Shopping. Revista Cerrado, v. 16, n. 1, p. 204-232, 2018.

SOUSA, Jailson de Macedo. A cidade na região e a região na cidade: a dinâmica socioeconômica de Imperatriz e suas implicações na região tocantina. Imperatriz: Ética editora, 2009.

SOUSA, Jailson de Macedo. As formas atuais da urbanização Amazônia e os seus reflexos na produção do espaço urbano de Imperatriz-MA. XIII SIMPURB UERJ. 18 a 22 de novembro de 2013. 22p.

SOUSA, Jailson de Macedo. Enredos da dinâmica urbano-regional Sulmaranhense: reflexões a partir da centralidade econômica de Açailândia, Balsas e Imperatriz. (Tese de Doutorado). Universidade Federal de Uberlândia/Programa de Pós-graduação em Geografia, 2015. $558 \mathrm{p}$.

SOUSA, Jailson de Macedo. Reestruturação urbano-regional amazônica e seus reflexos na produção do espaço urbano de ImperatrizMA. Caderno de Geografia, v. 28, n. 52, p. 79-105, 2018.

SOUSA, Jailson de Macedo; OLIVEIRA, Helbaneth; CARVALHO, Sheryda. Cidades em cena na Amazônia oriental: agentes, dinâmicas e processos. $1^{\mathrm{a}} \mathrm{ed}$. Imperatriz: editora vieira, 2018 
TRIVIÑOS, Augusto N. S. Introdução à pesquisa em ciências sociais: a pesquisa qualitativa em educação. São Paulo: Atlas, 1987.

VASCONCELOS, Pedro de Almeida. Aplicação do conceito de segregação residencial ao contexto brasileiro na longa duração. CIDADES. v. 1, n. 2, 2004, p. 259-274.

VOLOCHKO, Danilo. A produção do espaço e as estratégias reprodutivas do capital: negócios imobiliários e financeiros em São Paulo. (Tese de Doutorado). Universidade de São Paulo, 2008. 